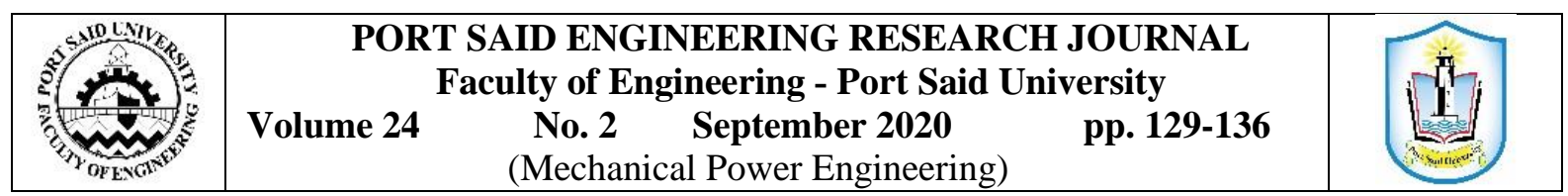

\title{
Simulation Study and Experimental Position Control of Pneumatic Cylinder Using Sliding Mode Control with on/off Control Valves
}

\author{
Y. El-sayed ${ }^{1}$, M. Hammam ${ }^{2}$, G. A. Z. Mousa ${ }^{3}$ \& A. M. Abdul Aziz \\ Received: 26 January 2020; Accepted: 26 April 2020
}

\begin{abstract}
Simulation and experimental studies of pneumatic cylinder position control are introduced. High speed on-off solenoid air valve is used instead of the proportional control valve. Sliding mode control with error modification (SMCE) is proposed to drive the air valves with pulse width modulation (PWM) technique. Comparison of the performance of the closed loop position control using SMCE with the traditional PID is held. The simulation model is used to optimize the SMC and PID controller parameters to start the experimental test as a first trial. The experimental results for square and sinusoidal position reference show superiority of the SMCE over the PID in terms of lower steady state errors, faster settling time, and less overshoot. The root mean square error for a sinusoidal input of $0.1 \mathrm{~Hz}$ is $0.22 \mathrm{~mm}$ for SMCE and $0.69 \mathrm{~mm}$ for PID controller. The maximum absolute errors are $0.66 \mathrm{~mm}$ and $1.46 \mathrm{~mm}$ for SMCE and PID, respectively.
\end{abstract}

Keywords: Pneumatic cylinder, position control, SMC, PWM, solenoid valves.

\section{INTRODUCTION}

Pneumatic systems are widely used in the industry due to their low cost, self-cooling, safe on the environment compared with other actuators, and its simplicity. The major drawback of pneumatic systems is their non-linear behavior due to the compressibility of the air, the friction between the piston and cylinder and the discontinuous regime of air flow through the control valves. These nonlinearities cause some difficulty to obtain appropriate control of the pneumatic actuator position. Non-linear model was studied in [1-5] to achieve an accurate position control. The position of the pneumatic cylinder can be controlled by adjusting the air flow rate entering the cylinder using either proportional control valves or on/off valves. Ren et al., [6], used proportional control valve to control the position of a rodless cylinder and obtained a high positioning accuracy. However, this valve is very expensive. PWM technique was used to drive low cost on/off solenoid valves to improve the positioning accuracy with several control methods, [7-11]. Salim et al., [12], used a self-regulated nonlinear PID and compared the results with conventional nonlinear PID. It was stated that the self-regulated technique improved both the

\footnotetext{
${ }^{I}$ Demonstrator, Mechanical Power Engineering Department, Faculty of Engineering, Port Said University, Egypt, corresponding author, email: y.elsayed@eng.psu.edu.eg

${ }^{2}$ Assistant professor, Mechanical Power Engineering Department, Faculty of Engineering, Port Said University, Egypt, email: m.hammam@eng.psu.edu.eg

${ }^{3}$ Assistant professor, Mechanical Power Engineering Department, Faculty of Engineering, Port Said University, Egypt, email: gazmousa@hotmail.com

${ }^{4}$ Professor, Mechanical Power Engineering Department, Faculty of Engineering, Ain Shams University, Cairo, Egypt, email:

abdelaziz_morgan@psu.asu.edu.eg

DOI : $10.21608 /$ pserj.2020.22883.1030
}

transient and the steady state response. Neural and fuzzy control schemes were used in [13-17] to optimize the gains of PID controller. Adaptive state feedback controller was used in $[18,19]$ to control the position of a double-acting rod less pneumatic cylinder using a proportional control valve. Zhang et al.,[20], used two methods of sliding mode control(SMC3 and SMC7), to control the opening and closing of four on/off control valves according to the sign of a second order sliding surface. It was found that the performance of the two control algorithms are similar and recommend to use the SMC3 because it doesn't require pressure sensor. Soleymani et al., [21], applied a SMC with multiple sliding surfaces to increase the position accuracy, but an extra pressure sensor was needed to feed the pressure signal to the control system. Jouppila et al., [22], made a comparative study of three valve configurations with SMC method to control the position of pneumatic muscle. The robustness of each configuration was tested by changing the load.

In this study, high speed on/off control valves are used to control the position of a pneumatic cylinder using SMC strategy of first order sliding surface with error modified by variable gain.

\section{EXPERIMENTAL SET-UP}

A photo of the electro-pneumatic positioning test rig and its schematic diagram are shown in Fig.1 and Fig.2.

The experimental test rig is mainly composed of two circuits are pneumatic circuit and electrical circuit. The purpose of the pneumatic circuit is to supply air to the pneumatic cylinder while the electrical circuit is used to drive the solenoids of the control valves. The pneumatic circuit is mainly composed of a double acting cylinder provided with a linear potentiometer and four on-off fast 
control valves. The cylinder is a single rod of type CD85N20-160-B which has a dimension of $20 \mathrm{~mm}$ bore and $158 \mathrm{~mm}$ stroke. The cylinder is mounted in a vertical direction. Air service unit composed of filter, pressure regulator and lubricator is used to supply the conditioned air to the cylinder. Fig. 3 shows a detailed construction of high speed air valve which works at high frequency up to $150 \mathrm{~Hz}$. It is mounted on the cylinder opening ports to supply and discharge air to and from the cylinder with the required air quantities. The piston position is measured using a linear potentiometer with linearity of $0.5 \%$.

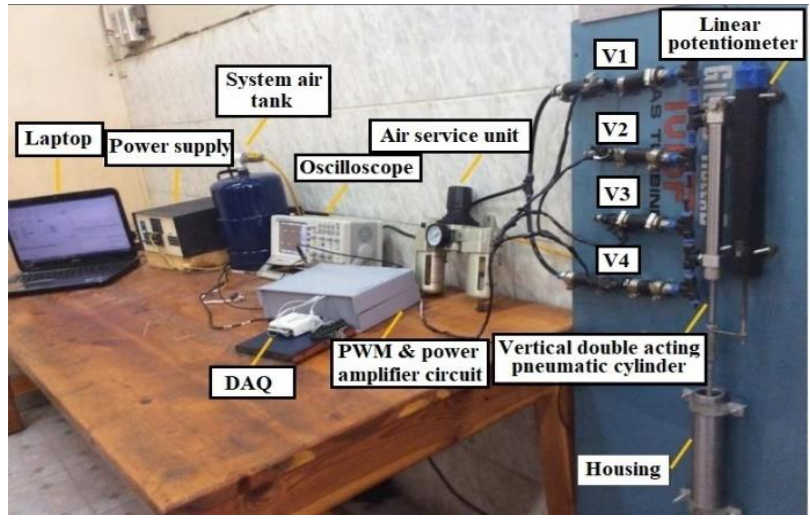

Figure 1: A photo of the experimental test rig

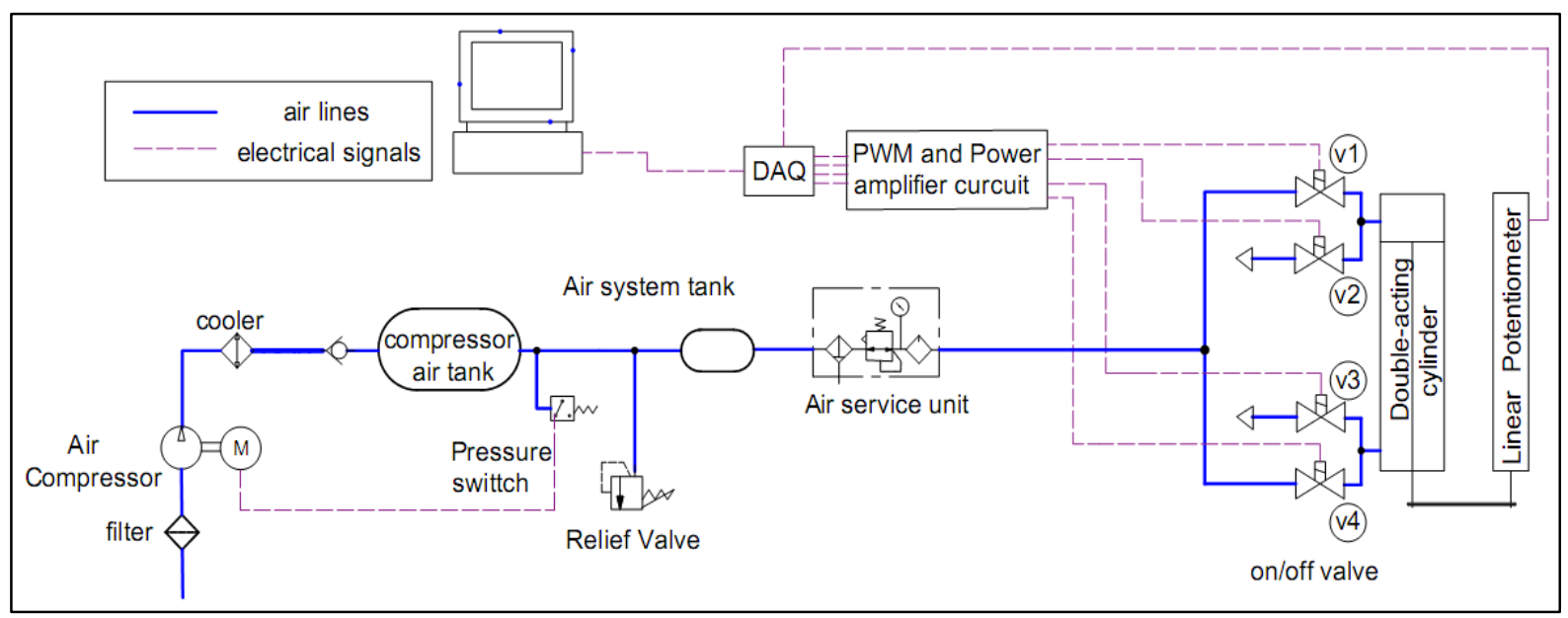

Figure 2: Schematic diagram of the experimental test rig

The electrical circuit consists of a PWM stage and power amplifier stage, as shown in Fig. 4. The PWM circuit is composed of a timer, digital to analog converter to produce a saw tooth signal. A comparator is used to compare the control action signal with the saw tooth signal to produce the variable duty signal that directly drives the control valves. The power amplifier circuit consists of three stage transistor to provide the solenoid valves with the required electric current.

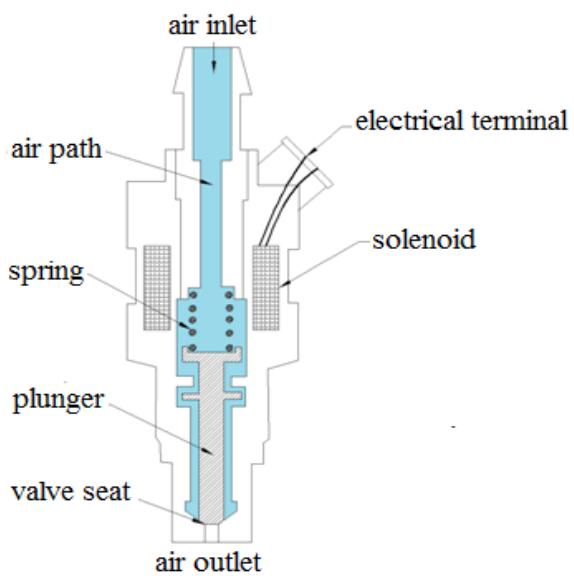

Figure 3: On/off solenoid valve

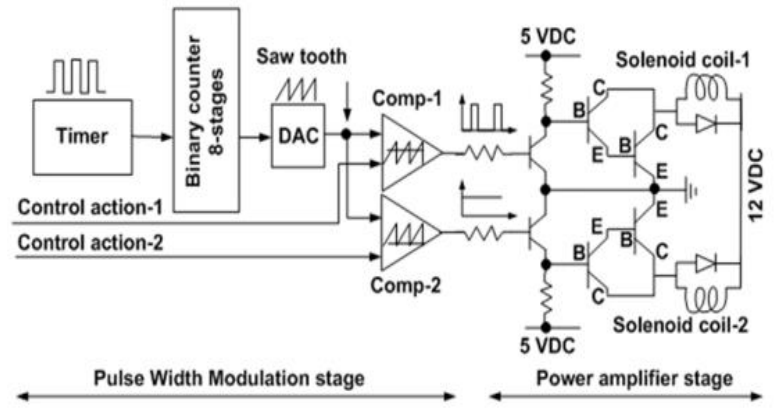

Figure 4: Pulse width modulation and power circuits

A personal Compute is to control the whole system through a National Instrument interface data acquisition card, NIUSB6009, DAQ, attached to it. DAQ is used to read the current piston position and to send the appropriate control action signal to the valves drive circuits. The control action is decided by a control software program written by the author using Lab View. The current control action is decided according to data fed to the control software, namely: the current position data from DAQ, reference position value by the user and the selected control scheme. 


\section{MATHEMATICAL MODEL OF THE PNEUMATIC POSITIONING CONTROL SYSTEM}

The mathematical model of the in-cylinder parameters is based on the fundamental equations of mass and energy in the transient state. The electro-pneumatic system is mainly composed of a double-acting pneumatic cylinder, the forces acting on it is shown in Fig. 5.

The dynamic pressures in each chamber are given by the following differential equations, [23]:

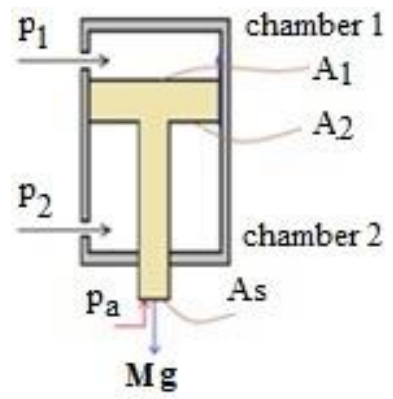

Figure 5: Forces acting on the cylinder

$$
\begin{aligned}
& \dot{p}_{1}=\frac{k}{V_{1}}\left[R\left(\dot{m}_{i 1} T_{i}-\dot{m}_{o 1} T_{1}\right)-A_{1} p_{1} \dot{y}\right] \\
& \dot{p}_{2}=\frac{k}{V_{2}}\left[R\left(\dot{m}_{i 2} T_{i}-\dot{m}_{o 2} T_{2}\right)+A_{2} p_{2} \dot{y}\right]
\end{aligned}
$$

Where $V_{1}, V_{2}$ are the volume of chamber 1 and chamber 2 respectively, $\dot{m}_{i 1}$ is the mass flow rate interring chamber 1 , $\dot{m}_{o 1}$ is the mass flow rate exiting the chamber $1, \dot{m}_{i 2}$ is the mass flow rate interring chamber $2, \dot{m}_{o 2}$ is the mass flow rate exiting chamber $2, \mathrm{R}$ is the specific gas constant for air, $\mathrm{k}$ is the specific heat ratio, $T_{i}$ is the supply air temperature, $T_{1}, T_{2}$ are the temperatures of air inside chamber 1 and chamber 2 respectively.

The in-cylinder temperatures are given by the following differential equations:

$\dot{T}_{1}=\left(k T_{i}-T_{1}\right) \frac{R \dot{m}_{i 1}}{P_{1} V_{1}} T_{1}-(k-1) \frac{R \dot{m}_{o 1}}{P_{1} V_{1}} T_{1}^{2}-(\mathrm{k}-1) \frac{\dot{V}_{1}}{V_{1}} T_{1}$

$\dot{T}_{2}=\left(k T_{i}-T_{2}\right) \frac{R \dot{m}_{i 2}}{p_{2} V_{2}} T_{2}-(k-1) \frac{R \dot{m}_{o 2}}{p_{2} V_{2}} T_{2}{ }^{2}-(\mathrm{k}-1) \frac{\dot{V}_{1}}{V_{1}} T_{2}$

The volumes of chamber 1 and 2 are:

$$
\mathrm{V}_{1}=\mathrm{A}_{1} \mathrm{y} \quad \text { and } \quad \mathrm{V}_{2}=\mathrm{A}_{2}(L-y)
$$

Where $\mathrm{L}$ is the stoke length.

Considering the cylinder opening as an orifice, the air mass flow rate through it can be calculated as follows, [24]:

$\dot{m}=A_{v} C_{d} p_{u} \sqrt{\frac{2}{r T_{u}}} \begin{cases}\left(\frac{2}{k+1}\right)^{1 / k-1} \sqrt{\frac{k}{k+1}} & \text { if } 0<\operatorname{Pr} \leq \operatorname{Pcr} \\ \sqrt{\frac{k}{k-1}\left[(p r)^{\frac{2}{k}}-(p r)^{\frac{k+1}{k}}\right]} & \text { if } \operatorname{Pcr}<\operatorname{Pr} \leq 1 \\ 0 & \text { if } 1<\operatorname{Pr}\end{cases}$

Where, $A_{v}$ is the orifice passage area, $C_{d}$ is the coefficient of discharge, $\mathrm{P}_{\mathrm{r}}$ is the ratio of downstream pressure to upstream pressure, $\mathrm{p}_{\mathrm{u}}$ is upstream pressure, $\mathrm{p}_{\mathrm{d}}$ is downstream pressure, $\mathrm{T}_{\mathrm{u}}$ is the upstream temperature, and $\mathrm{P}_{\mathrm{cr}}$ is the critical pressure ratio

$$
\begin{gathered}
\mathrm{P}_{\mathrm{cr}}=\left(\frac{2}{k+1}\right)^{\frac{k}{k-1}}=0.528 \\
\mathrm{P}_{\mathrm{r}}=\frac{p_{d}}{p_{u}}
\end{gathered}
$$

The direction of mass flow rate through the cylinder is determined according to the pressure difference between the in-cylinder pressure and outside pressure.

The piston downward motion is governed by forces acting on it from both sides according to Newton's second law as follows:

$$
\mathrm{M} \ddot{y}=\mathrm{p}_{1} \mathrm{~A}_{1}-\mathrm{p}_{2} \mathrm{~A}_{2}-\mathrm{p}_{\mathrm{a}} \mathrm{A}_{\mathrm{s}}+\mathrm{Mg}-\mathrm{C}_{\mathrm{v}} \dot{y}-\mathrm{F}_{\mathrm{f}}
$$

Where $\mathrm{M}$ is the total mass of both piston and load, $p_{1}, p_{2}$ are the pressures inside chamber 1 and chamber 2 respectively, $A_{1}$ and $A_{2}$ are the areas of piston for up and down faces, $\mathrm{P}_{\mathrm{a}}$ is the atmosphere pressure, $\mathrm{A}_{\mathrm{s}}$ is the area of the piston shaft, $C_{v}$ is the viscous coefficient and $F_{f}$ is the friction force.

The friction force was established by Messina [25] according to piston velocity and its direction as follows:

$$
F_{f}=\left\{\begin{array}{cl}
\left|F_{s}\right| \operatorname{sign}\left(F_{p}\right) & \text { if } \dot{y}=0 \text { and }\left|F_{p}\right| \geq\left|F_{s}\right| \\
\left|F_{p}\right| \operatorname{sign}\left(F_{p}\right) & \text { if } \dot{y}=0 \text { and }\left|F_{p}\right|<\left|F_{s}\right| \\
\left|F_{d}\right| \operatorname{sign}(\dot{y}) & \text { if } \dot{y} \neq 0
\end{array}\right.
$$

Where, $F_{s}$ is the static friction force, $F_{d}$ is the dry friction force and are determined experimentally. $F_{p}$ is the pressure force acting on the piston:

$$
F_{p}=p_{1} A_{1}-p_{2} A_{2}-p_{a} A_{s}
$$

\section{PNEUMATIC SYSTEM CONTROLLER DESCRIPTION}

The purpose of the controller is the switching algorithm between the on and off modes of valve operation.

The electro-pneumatic system contains four on/off valves with possible 16 mode of operation. Referring to Fig. 1, only three modes are used to drive the pneumatic cylinder as shown in table 1

Where $\mathbf{v}_{1}$ and $\mathbf{v}_{2}$ are the supply and exhaust valves for chamber 1 and $\mathbf{v}_{\mathbf{3}}$ and $\mathbf{v}_{\mathbf{4}}$ are the supply and exhaust valves for chamber 2 .

Table 1: Valves operation modes

\begin{tabular}{|c|c|c|c|c|c|}
\hline & \multicolumn{4}{|c|}{ valve } & Motion \\
& virection \\
\hline Mode 1 & 1 & 0 & 1 & 0 & Downward \\
\hline Mode 2 & 0 & 1 & 0 & 1 & upward \\
\hline Mode 3 & 0 & 0 & 0 & 0 & hold \\
\hline
\end{tabular}

The valves connected to the pressurized air supply source (valve 1 and valve 4) are driven by Pulse Width Modulation signal with duty ratio determined according to the value of the control signal $u$. The other exhausting two valves $\mathbf{v} 2$ and $\mathbf{v} 3$ are opened or closed completely. The sliding mode control algorithm, SMC, is proposed to determine the appropriate control action.

SMC is a form of variable structure control. It is considered as an efficient tool to design robust controllers for complex 
high-order nonlinear dynamic plant operating under uncertain conditions.[26] The objective is to force the system trajectory to reach sliding manifold or (sliding surface) in a finite time as shown in Fig. 6, then the control action is used to maintain the system on the sliding surface and force it to the origin point. The sliding surface is chosen to be first order as

$$
\mathrm{s}=\dot{e}+\lambda e
$$

Where e is the position error $\left(\mathrm{y}_{\text {ref }}-\mathrm{y}\right), \mathrm{y}_{\text {ref }}$ is the reference position, $y$ is the actual position and $\lambda$ is a sliding surface constant. The control signal $u$ is determine from the sign of the sliding surface as

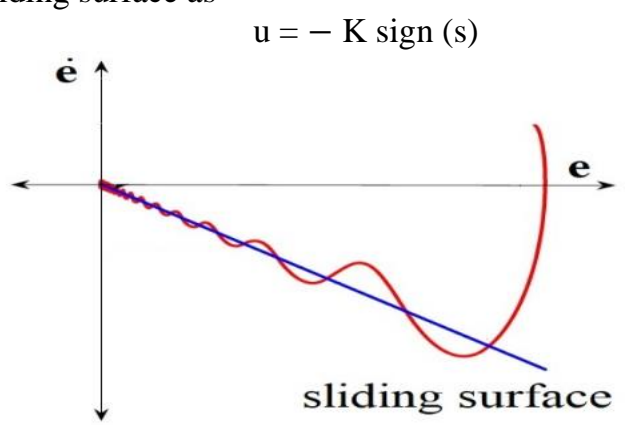

Figure 6: Sliding mode concept
There are two cases of the gain $\mathrm{k}$ :

Case 1: Constant controller gain. The control signal have only two values ( $\mathrm{K}$ or $-\mathrm{K})$. The positive value operates mode 1 in table 1 , while the negative value operates mode2.

Case 2: variable controller gain proportional to the position error as

$$
\mathrm{K}=\mathrm{k}_{\mathrm{c}}|e(t)|
$$

The controller action in this case constitutes the duty ratio of the PWM signal corresponding to the value of the control signal $u$. This type of control will be called SMCE.

\section{THE MODEL SIMULATION}

MATLAB/ SIMULINK is used to simulate the equations of the electro-pneumatic model with the implemented controller. Fig. 7 summarizes the main frame work of the Simulink model through the simulation parameters listed in table 2 .

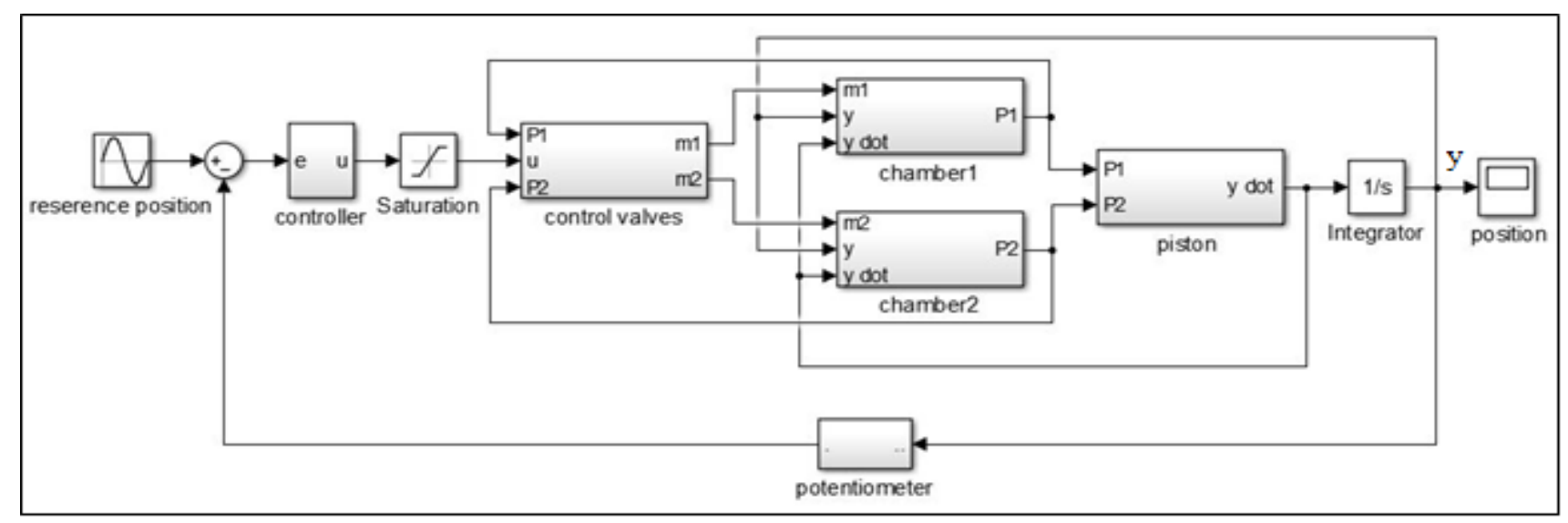

Figure 7: Simulink model for the electro-pneumatic positioning system

Table 2.The simulation parameters

\begin{tabular}{|c|c|}
\hline Parameter & Value \\
\hline $\mathrm{Ps}$ & $700000 \mathrm{pa}$ \\
\hline $\mathrm{Pa}$ & $100000 \mathrm{pa}$ \\
\hline $\mathrm{Ta}$ & $300 \mathrm{k}$ \\
\hline $\mathrm{ds}$ & $8 \mathrm{~mm}$ \\
\hline $\mathrm{d} 1$ & $20 \mathrm{~mm}$ \\
\hline $\mathrm{L}$ & $160 \mathrm{~mm}$ \\
\hline $\mathrm{k}$ & 1.4 \\
\hline $\mathrm{R}$ & $287 \mathrm{~J} / \mathrm{kg} . \mathrm{k}$ \\
\hline $\mathrm{M}$ & $0.5 \mathrm{~kg}$ \\
\hline $\mathrm{C}_{\mathrm{v}}$ & $5 \mathrm{~N} . \mathrm{s} / \mathrm{m}$ \\
\hline $\mathrm{C}_{\mathrm{d}}$ & 0.6 \\
\hline $\mathrm{Av}$ & $1.8096 \mathrm{e}-07 \mathrm{~m}^{2}$ \\
\hline $\mathrm{Fs}$ & 18 \\
\hline $\mathrm{Fd}$ & 7 \\
\hline
\end{tabular}

The values of the parameter listed in table 2 are corresponding to the experimental test rig condition

\section{RESULTS}

\subsection{Constant and variable gain of SMC}

The first section of the result shows the performance of position control loop using SMC and SMCE controller type subjected to sinusoidal tracking signal.

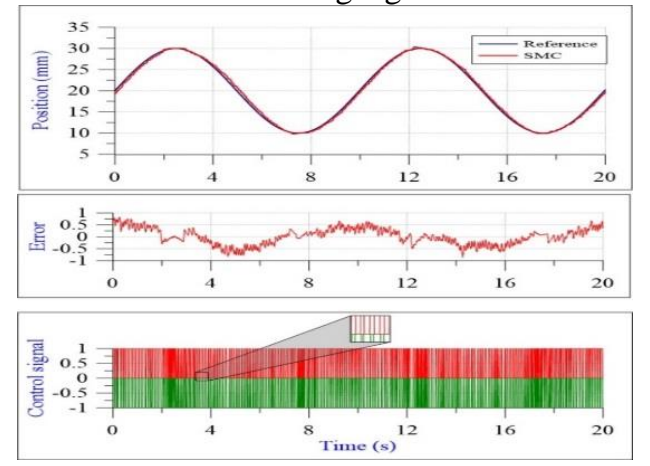

Figure. 8: Control signal corresponding to constant gain (SMC) , $\lambda=25$ 
Fig. 8 shows the position, error and control signal for the first case of SMC with constant gain $\mathrm{K}=1$.The control signal obviously has only two values and the control valves are either completely open or completely closed. The value of the RMSE is $0.34 \mathrm{~mm}$ during this test.
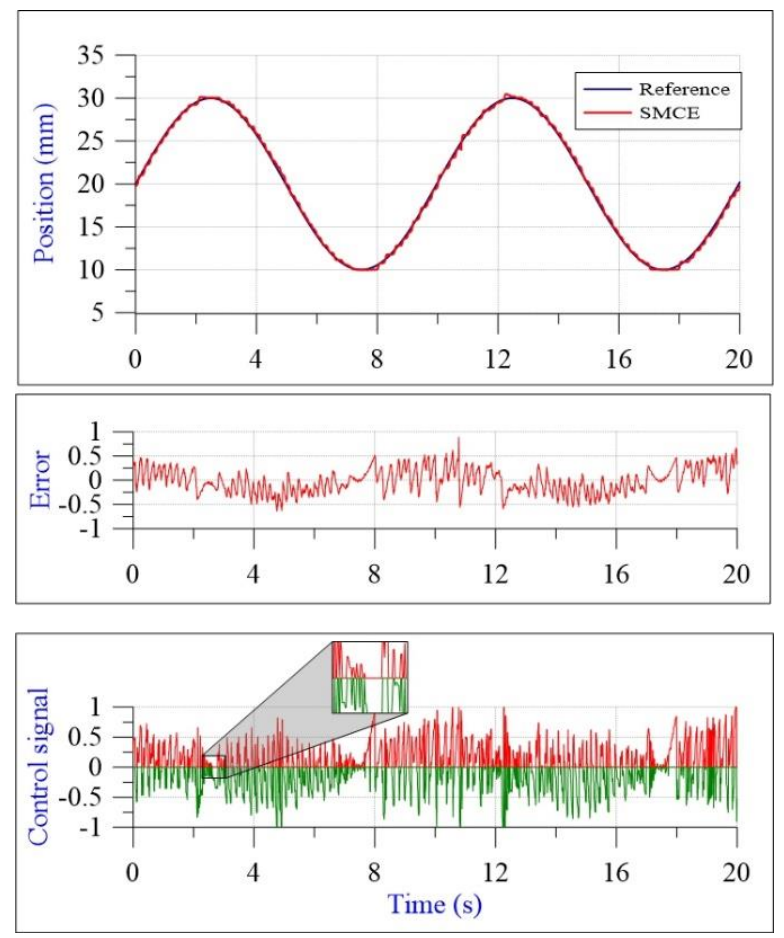

Figure 9: Control signal corresponding to variable gain (SMCE), $\lambda=25$ and $\mathrm{k}_{\mathrm{c}}=7$

Fig.9 shows the results of same test using the second case of SMCE with variable gain by error modification As shown in figure the control signal has a several values and the control valves operate by a variable duty ratio. The value of RMSE is $0.22 \mathrm{~mm}$ which is $32 \%$ less than $\mathrm{SMC}$. Therefore the SMCE is selected in the present study and is compared with the PID controller which is widely used in the majority of the industrial applications.

\subsection{Controller parameter selection.}

\subsubsection{Parameter of SMCE.}

The parameters, $\lambda$ and $\mathrm{k}_{\mathrm{c}}$ of SMCE are determined, as a first estimate, from the simulation model with the system parameter listed in table 2. The optimum controller parameters are then selected from a set of simulation runs shown in Fig 10.

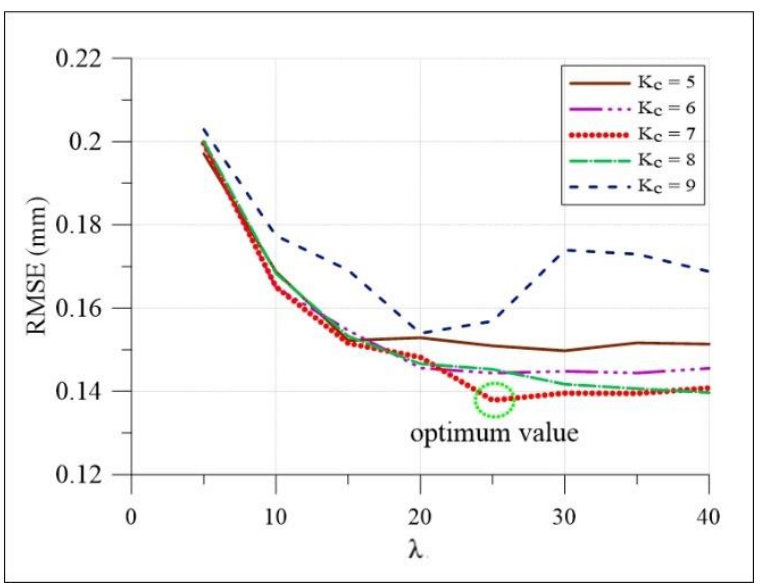

Figure 10: SMCE parameter optimization

The best values which give the least RMSE are $\lambda=25$ and $k_{c}=7$. These parameters are then used in the experimental study to save time of practical experiments. Moreover, the results are produced in constant temperature environment which is difficult to attain in real experiment due to the heat accumulation which negatively affects the accuracy of the results.

\subsubsection{Determination of optimum parameters for the PID controller}

Evaluation the PID controller parameters is based on Zigular-Nicholas tuning method. The result is shown in Fig. 11 where the critical period is $0.33 \mathrm{~s}$ and the critical gain is 3 .

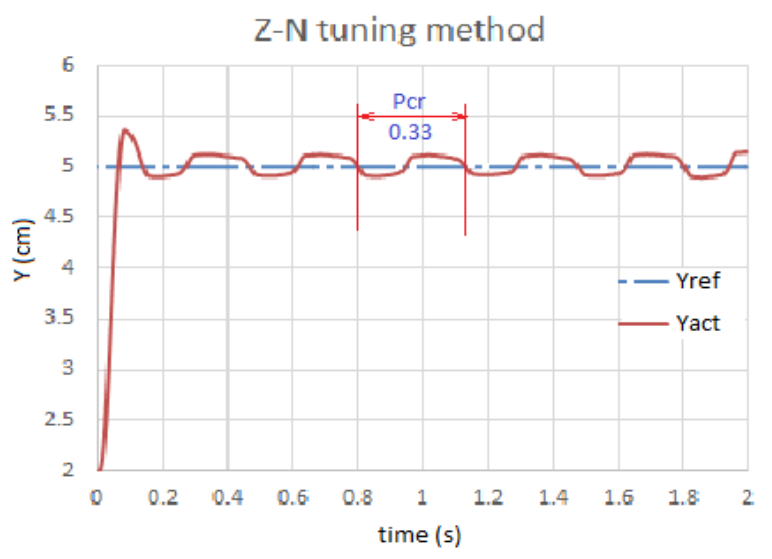

Figure 11: Output waveform oscillation corresponding to $\mathbf{k}_{\mathrm{cr}}=3$

The optimized PID controller parameters are then:

$$
\begin{gathered}
\mathrm{k}_{\mathrm{p}}=1.8, \\
\mathrm{~T}_{\mathrm{i}}=0.165 \text { and } \\
\mathrm{T}_{\mathrm{d}}=0.04125
\end{gathered}
$$

\subsubsection{Experimental result.}

A comparison between the present SMCE controller and the optimized PID is presented for square and sinusoidal reference inputs. The effect of input frequency on system error is also studied. The performance of both controllers 
is compared according to the maximum steady state error and the average root mean square error.

\subsubsection{Square reference.}

Results of Fig. 12 indicate that the SMCE reaches steady state faster than PID with less steady state error. The maximum steady state error, MSSE, is $0.15 \mathrm{~mm}$ for SMCE and $0.5 \mathrm{~mm}$ for PID. It is also clear that the cylinder position, in case of the PID, sticks away from the reference position for some time when the reference position is suddenly changed.

\subsubsection{Sinusoidal reference.}

The controllers are tested at four input frequencies, 0.05, $0.1,0.2$ and $0.3 \mathrm{~Hz}$. As a general remark, the error increases, for both controllers, as the input frequency increases. However the errors associated with the SMCE are much lower than that of the PID. Figs. 13-16 show the position and error signals at the tested frequencies.

Table 3 summarizes the error values for both SMCE and PID controllers.

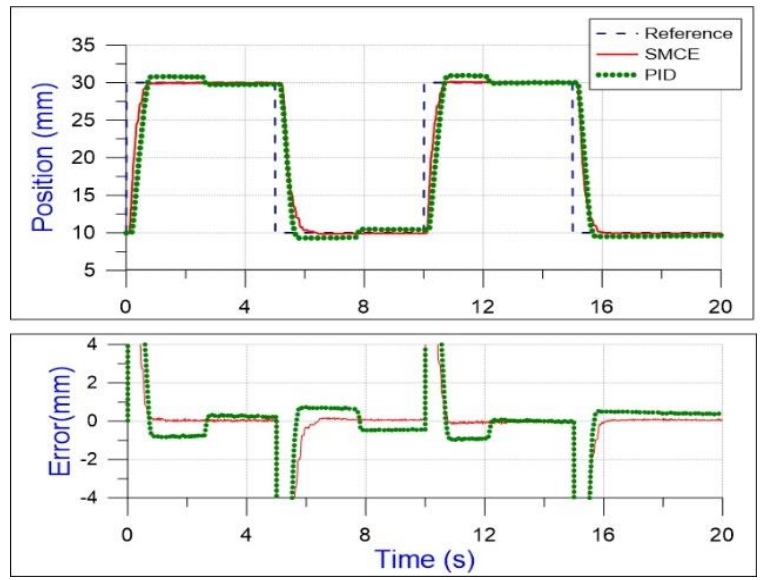

Figure 12: Experimental results of cylinder position control to a reference in the form of square wave, with $0.1 \mathrm{~Hz}$ and amplitude of $10 \mathrm{~mm}$

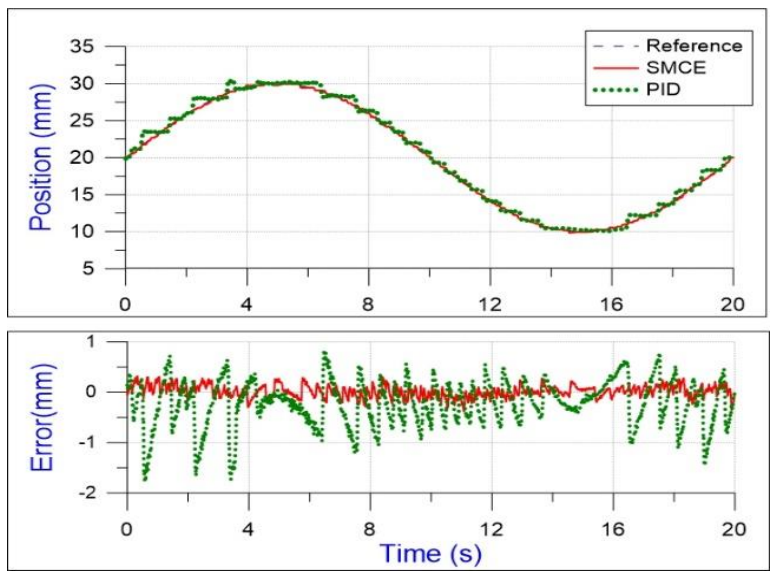

Figure 13: Experimental results of cylinder position control to a reference in the form of sin wave, with $0.05 \mathrm{~Hz}$ and amplitude of $10 \mathrm{~mm}$.
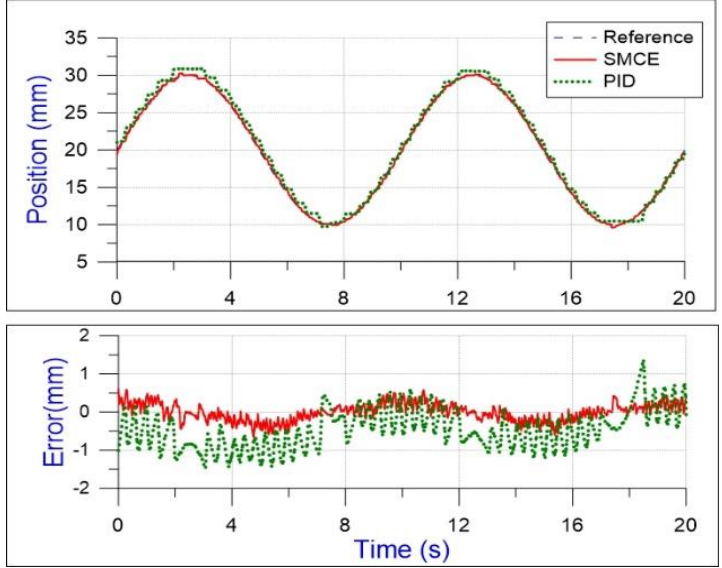

Figure 14: Experimental results of cylinder position control to a reference in the form of sin wave, with $0.1 \mathrm{~Hz}$ and amplitude of $10 \mathrm{~mm}$.

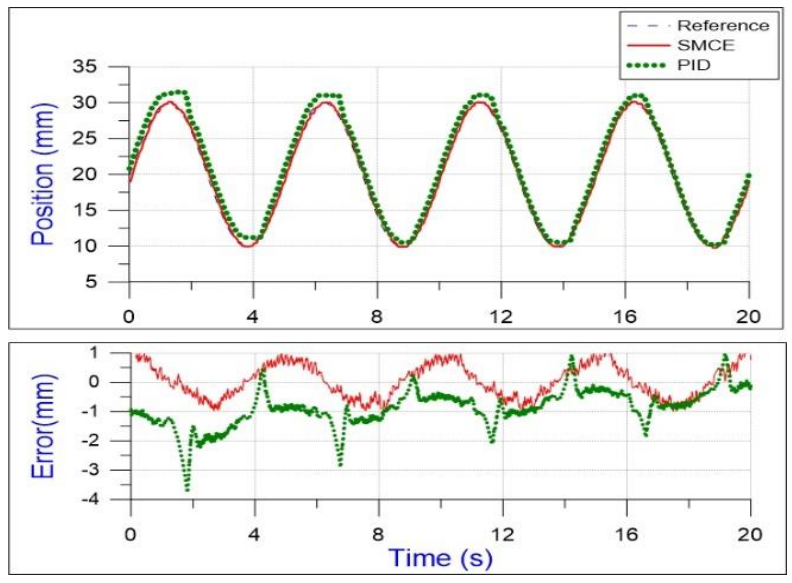

Figure 15: Experimental results of cylinder position control to a reference in the form of sin wave, with $0.2 \mathrm{~Hz}$ and amplitude of $10 \mathrm{~mm}$.

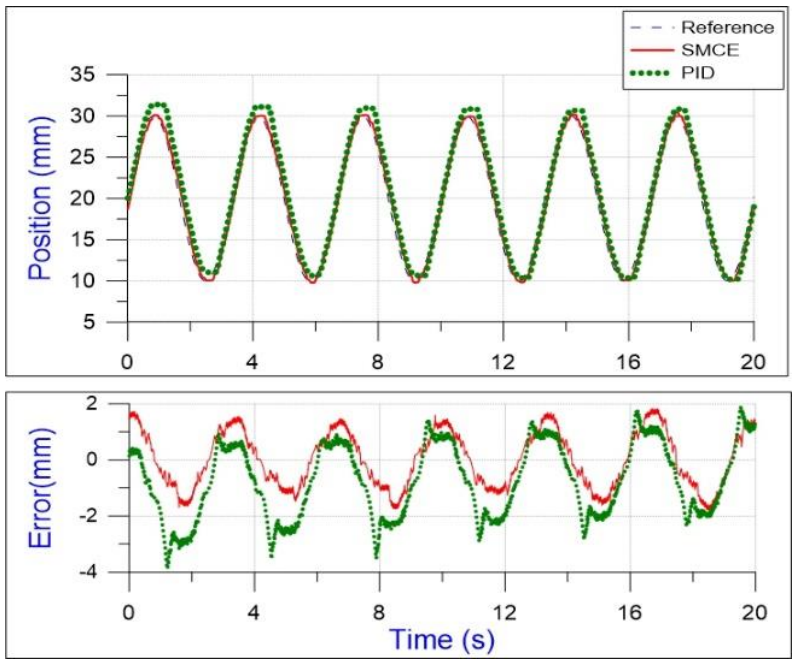

Figure 16: Experimental results of cylinder position control to a reference in the form of sin wave, with $0.3 \mathrm{~Hz}$ and amplitude of $10 \mathrm{~mm}$. 
Table 3: Error test results the experimental SMCE and PID controllers in ( $\mathrm{mm})$.

\begin{tabular}{|c|c|c|c|c|}
\hline \multirow{2}{*}{$\begin{array}{c}\text { Referance } \\
\text { frequencies }\end{array}$} & \multicolumn{2}{|c|}{ SMCE } & \multicolumn{2}{c|}{ PID } \\
\cline { 2 - 5 } & RMSE & MAE & RMSE & MAE \\
\hline $0.05 \mathrm{~Hz}$ & 0.11 & 0.38 & 0.5 & 1.77 \\
\hline $0.1 \mathrm{~Hz}$ & 0.22 & 0.66 & 0.69 & 1.46 \\
\hline $0.2 \mathrm{~Hz}$ & 0.57 & 1.36 & 1.09 & 3.69 \\
\hline $0.3 \mathrm{~Hz}$ & 0.99 & 1.75 & 1.53 & 3.88 \\
\hline
\end{tabular}

The maximum error always occurs at the beging and end of cylinder stroke where it is difficult to track due to the high piston acceleration.

\section{CONCLUSION}

A simple controller of SMC which does not require a full state definition of the system model is adopted. The suggested controller depends on the sliding surface definition and the absolute value of the position error only. The main concluded remarks are:

1 - For a square reference position, the MSSE is decreased by nearly three times when SMCE is used instead of PID controller.

2- The cylinder position for SMCE reaches steady state faster than PID control and there is no overshoot.

3- For sinusoidal reference position, the RMSE and MAE for SMCE controller are less than that in PID controller.

4- The RMSE for SMCE is always less than that of the PID through the whole tested range of sinusoidal input frequencies

\begin{tabular}{|c|c|}
\hline Abbreviations & \\
\hline Comp & Comparator \\
\hline DAC & Digital to analog converter \\
\hline MAE & Maximum absolute error \\
\hline MSSE & Maximum steady state error \\
\hline PID & $\begin{array}{l}\text { Proportional plus integral plus } \\
\text { derivative control }\end{array}$ \\
\hline PWM & Pulse width modulation \\
\hline RMSE & Root mean square error \\
\hline SMC & Sliding mode control \\
\hline SMCE & Sliding mode control with error \\
\hline
\end{tabular}

\section{Nomenclature}

$\begin{array}{ll}A_{1} & \text { chamber } 1 \text { cross section area, } \mathrm{m}^{2} \\ \mathrm{~A}_{2} & \text { chamber } 2 \text { cross section area, } \mathrm{m}^{2} \\ \mathrm{~A}_{\mathrm{s}} & \text { piston shaft cross section area, } \mathrm{m}^{2} \\ \mathrm{~A}_{\mathrm{v}} & \text { valve orifice area, } \mathrm{m}^{2} \\ \mathrm{C}_{\mathrm{v}} & \text { viscous friction coefficient } \\ \mathrm{e} & \text { error signal } \\ \mathrm{F}_{\mathrm{d}} & \text { dynamic friction force, } \mathrm{N} \\ \mathrm{F}_{\mathrm{f}} & \text { friction force, } \mathrm{N} \\ \mathrm{F}_{\mathrm{s}} & \text { static friction force, } \mathrm{N} \\ \mathrm{K} & \text { SMC gain } \\ \mathrm{k} & \text { specific heats ratio } \\ \mathrm{k}_{\mathrm{c}} & \text { SMC gain constant } \\ \mathrm{K}_{\mathrm{p}} & \text { PID proportional gain } \\ \mathrm{L} & \text { cylinder maximum length, } \mathrm{m} \\ \mathrm{M} & \text { total mass of piston and load, } \mathrm{kg} \\ \dot{m} & \text { air mass flow rate, kg/s }\end{array}$

$\begin{array}{ll}\mathrm{p}_{1} & \text { pressure in chamber } 1, \mathrm{~Pa} \\ \mathrm{p}_{2} & \text { pressure in chamber } 2, \mathrm{~Pa} \\ \mathrm{p}_{\mathrm{a}} & \text { atmosphere pressure, } \mathrm{Pa} \\ \mathrm{P}_{\mathrm{cr}} & \text { critical pressure ratio } \\ \mathrm{P}_{\mathrm{r}} & \text { valve downstream to upstream pressure ratio } \\ \mathrm{R} & \text { specific gas constant of air, J/kg K } \\ \mathrm{s} & \text { sliding surface } \\ \mathrm{T}_{1} & \text { air temperature in chamber } 1, \mathrm{~K} \\ \mathrm{~T}_{2} & \text { air temperature in chamber } 2, \mathrm{~K} \\ \mathrm{~T}_{\mathrm{d}} & \text { PID derivative time constant, } \mathrm{S} \\ \mathrm{T}_{\mathrm{i}} & \text { supply air temperature, } \mathrm{K} \\ \mathrm{T}_{\mathrm{i}} & \text { PID integration time constant, } \mathrm{s} \\ \mathrm{u} & \text { control signal } \\ \mathrm{V}_{1} & \text { volume of chamber } 1, \mathrm{~m}^{3} \\ \mathrm{~V}_{2} & \text { volume of chamber } 2, \mathrm{~m}^{3} \\ \mathrm{y} & \text { cylinder position, } \mathrm{m} \\ \mathrm{y}_{\mathrm{ref}} & \text { reference position, } \mathrm{m} \\ \lambda & \text { sliding surface constant }\end{array}$

\section{CREDIT AUTHORSHIP CONTRIBUTION STATEMENT:}

Y. El-sayed Software, Resources, Investigation, Data Curation, Writing - Original Draft, M. Hammam: Validation, Writing - Review \& Editing G.A.Z.Mousa: Methodology, Formal analysis, Writing Review \& Editing,. A. M. Abdul Aziz: Conceptualization, Investigation, Resources

\section{DECLARATION OF COMPETING INTEREST}

The authors declare that they have no known competing financial interests or personal relationships that could have appeared to influence the work reported in this paper.

\section{REFERENCES}

[1] P. L. Andrighetto, A. C. Valdiero, and L. Carlotto, "Study of the friction behavior in industrial pneumatic actuators," in ABCM Symposium series in mechatronics, 2006, pp. 369-376.

[2] Z. Rao and G. M. Bone, "Nonlinear modeling and control of servo pneumatic actuators," IEEE transactions on control systems technology, vol. 16, pp. 562-569, 2008.

[3] C. S. Ritter, A. C. Valdiero, P. L. Andrighetto, L. Endler, and F. Zago, "Nonlinear characteristics systematic study in pneumatic actuators," in Proceedings of the 20th International Congress of Mechanical Engineering, 2009.

[4] A. C. Valdiero, C. S. Ritter, C. F. Rios, and M. Rafikov, "Nonlinear mathematical modeling in pneumatic servo position applications," Mathematical Problems in Engineering, vol. 2011, 2011.

[5] Y. Tassa, T. Wu, J. Movellan, and E. Todorov, "Modeling and identification of pneumatic actuators," in 2013 IEEE International Conference on Mechatronics and Automation, 2013, pp. 437-443.

[6] H. Ren and J. Fan, "Adaptive backstepping slide mode control of pneumatic position servo system," Chinese Journal of Mechanical Engineering, vol. 29, pp. 10031009, 2016.

[7] M. Taghizadeh, A. Ghaffari, and F. Najafi, "A linearization approach in control of PWM-driven servopneumatic systems," in 2008 40th Southeastern 
Symposium on System Theory (SSST), 2008, pp. 395399.

[8] M. Taghizadeh, A. Ghaffari, and F. Najafi, "Improving dynamic performances of PWM-driven servopneumatic systems via a novel pneumatic circuit," ISA transactions, vol. 48, pp. 512-518, 2009.

[9] S. Hodgson, M. Tavakoli, M. T. Pham, and A. Leleve, "Nonlinear discontinuous dynamics averaging and PWM-based sliding control of solenoid-valve pneumatic actuators," IEEE/ASME Transactions on mechatronics, vol. 20, pp. 876-888, 2014.

[10]B. Najjari, S. M. Barakati, A. Mohammadi, M. J. Futohi, and M. Bostanian, "Position control of an electro-pneumatic system based on PWM technique and FLC," ISA transactions, vol. 53, pp. 647-657, 2014.

[11]D. Šešlija, S. Čajetinac, V. Blagojević, and J. Šulc, "Application of pulse width modulation and by-pass valve control for increasing energy efficiency of pneumatic actuator system," Proceedings of the Institution of Mechanical Engineers, Part I: Journal of Systems and Control Engineering, vol. 232, pp. 13141324, 2018.

[12]S. Salim, S. Najib, M. F. a. Rahmat, M. Faudzi, Z. H. Ismail, and N. Sunar, "Position control of pneumatic actuator using self-regulation nonlinear PID," Mathematical Problems in Engineering, vol. 2014, 2014.

[13]B. Dehghan and B. Surgenor, "Comparison of fuzzy and neural network adaptive methods for the position control of a pneumatic system," in 2013 26th IEEE Canadian Conference on Electrical and Computer Engineering (CCECE), 2013, pp. 1-4.

[14]S.-C. Hsu and C.-Y. Lin, "Periodic motion control of a heavy duty pneumatic actuating table using low-cost position sensors and hybrid repetitive control," in 2013 IEEE International Symposium on Industrial Electronics, 2013, pp. 1-6.

[15]S. Elbelady, H. Fawaz, and A. Abdul Aziz, "Online Self Tuning PID Control Using Neural Network for Tracking Control of a Pneumatic Cylinder Using Pulse Width Modulation Piloted Digital Valves," International Journal of Mechanical \& Mechatronics Engineering IJMME-IJENS, vol. 16, pp. 123-136, 2016.

[16]H. Fawaz and M. A. Aziz, ",Position control of a pneumatic actuator using digital valves and fuzzy PI controller"," International Journal of Mechanical and Mechatronics Engineering, vol. 16, pp. 10-22, 2016.
[17]A. A. Mansour, W. M. Hashim, and A. A. W. Muhammad, "Design and Implementation of a Pneumatic Servo System using Conventional Direction Control Valve," IRAQI JOURNAL OF COMPUTERS, COMMUNICATION AND CONTROL \& SYSTEMS ENGINEERING, vol. 18, pp. 1-11, 2018.

[18]H.-P. Ren and C. Huang, "Adaptive backstepping control of pneumatic servo system," in 2013 IEEE International Symposium on Industrial Electronics, 2013, pp. 1-6.

[19]H.-P. Ren and C. Huang, "Experimental tracking control for pneumatic system," in IECON 2013-39th Annual Conference of the IEEE Industrial Electronics Society, 2013, pp. 4126-4130.

[20]Y. Zhang and G. M. Bone, "Direct Switching Position Control Algorithms for Pneumatic Actuators using On/Off Solenoid Valves," 2018.

[21]F. Soleymani, S. M. Rezaei, M. Zareinejad, K. Baghestan, and A. Rahimi, "Position control of a servopneumatic actuator with mis-matched uncertainty using multiple-surface sliding mode controller and high-gain observer," Transactions of the Institute of Measurement and Control, vol. 39, pp. 1497-1508, 2017.

[22]V. T. Jouppila, S. A. Gadsden, G. M. Bone, A. U. Ellman, and S. R. Habibi, "Sliding mode control of a pneumatic muscle actuator system with a PWM strategy," International journal of fluid power, vol. 15, pp. 19-31, 2014.

[23]S. Liu and J. Bobrow, "An analysis of a pneumatic servo system and its application to a computercontrolled robot," Journal of Dynamic Systems, Measurement, and Control, vol. 110, pp. 228-235, 1988.

[24]P. Beater, "Pneumatic Drives: System Design, Modelling and Control. 2007," ed: Berlin Springer.

[25]A. Messina, N. I. Giannoccaro, and A. Gentile, "Experimenting and modelling the dynamics of pneumatic actuators controlled by the pulse width modulation (PWM) technique," Mechatronics, vol. 15, pp. 859-881, 2005.

[26]A. Sabanovic, L. Fridman, and S. Spurgeon, "Variable Structure Systems: From Principles to Implementation (IEE Control Engineering)," ed: Academic Press, Inc, 2004. 